\title{
Relations entre la dégradabilité in sacco des matières azotées des tourteaux de soja et leur composition chimique*
}

\author{
S Andres, J Gonzalez \\ Universidad politécnica, escuela técnica superior de ingenieros agrónomos, \\ departamento de producción animal, 28040 Madrid, Espagne
}

Ce travail a pour but d'étudier les variations de la dégradabilité théorique de l'azote de tourteaux de soja selon sa solubilité et sa proportion dans les parois.

Sur 6 tourteaux de soja d'origine différente, 5 déshuilés (échantillons $1-5$ ) et un expeller (échantillon 6), on a déterminé (tableau I): la teneur en azote du NDF et de l'ADF, la solubilité de l'azote après $6 \mathrm{~h}$ d'incubation dans la salive artificielle de Mc Dougall (1948) et la dégradation en sachets de l'azote dans le rumen, mesurée sur 3 moutons recevant $40 \mathrm{~g} \mathrm{MS} / \mathrm{kg} P^{0.75}$ d'une ration composée de foin et de concentré dans un rapport 2/1. Des sachets (pores de $46 \mu \mathrm{m}$ ) avec $3 \mathrm{~g}$ de tourteau broyé à la grille de $2 \mathrm{~mm}$ ont été placés pendant $2,4,8,16,24$ et $48 \mathrm{~h}$ dans le rumen ( 2 incubations par aliment et par animal). Les cinétiques de dégradation ont été ajustées par le modèle proposé par Ørskov et Mc Donald (1979) $D(t)=a+b$ $\left(1-e^{-c t}\right)$, et la dégradabilité théorique a été calculée en admettant une vitesse de passage dans le rumen des tourteaux de 0,05/h.
Les valeurs des fractions d'azote rapidement dégradable (a) et d'azote potentiellement dégradable $(b)$ ont été très semblables parmi les 6 tourteaux. Par contre, il y a des différences importantes entre les valeurs du taux horaire de dégradation (c), et par la suite de la $D T$, selon les conditions de préparation des tourteaux.

Aucune relation n'apparaît entre la $D T$ et l'azote soluble, mais la $D T$ peut être prédite avec précision à partir des teneurs en $\mathrm{N}$ du NDF et de l'ADF :

$$
\begin{gathered}
D T=69,28-2,25 \mathrm{~N}-\mathrm{NDF} ; R^{2}=0,864 ; \\
P<0,007 ; n=6 ; \mathrm{ETR}=2,65 ; \\
D T=62,88-2,09 \mathrm{~N}-\mathrm{NDF}+2,27 \mathrm{~N}-\mathrm{ADF} ; \\
R^{2}=0,976 ; P<0,003 ; n=6 ; \\
\text { ETR }=1,28 .
\end{gathered}
$$

Mc Dougall ER (1948) Biochem J 43, 99-106 Ørskov ER, Mc Donald I (1979) J Agric Sci Camb 92, 499-503

Tableau I. Composition, solubilité et dégradation dans le rumen de l'azote total (NT).

\begin{tabular}{lrrrrrrr}
\hline Échantillons & 1 & 2 & 3 & 4 & 5 & 6 & $E T$ \\
\hline Azote total (NT \% de MS) & 8,2 & 7,7 & 7,8 & 8,4 & 8,1 & 7,5 & \\
Azote du NDF (\% de NT) & 2,9 & 3,2 & 4,7 & 3,2 & 6,9 & 9,0 & \\
Azote de lADF (\% de NT) & 2,4 & 2,6 & 4,0 & 3,0 & 2,5 & 1,4 & \\
Azote soluble (\% de NT) & 30,2 & 27,6 & 20,6 & 19,3 & 17,5 & 16,5 & \\
Taux de dégradation (c; \%/h) & $5,5^{d e}$ & $6,0^{d}$ & $5,5^{d e}$ & $5,2^{d e}$ & $4,2^{e}$ & $2,4^{\prime}$ & 0,75 \\
Dégradabilité théorique (DT; \%) & $62,3^{d}$ & $62,2^{d e}$ & $61,7^{d e}$ & $61,6^{d e}$ & $57,7^{e}$ & $46,1^{t}$ & 2,36 \\
\hline
\end{tabular}

d. e. ' $:$ Les valeurs indicées de lettres distinctes sont différentes au niveau de $5 \%$.

* Ce travail a été financé par la CICYT, Projet GAN 89-126. 